Original Research Article

\title{
Causes of blindness in children attending blind school in north Karnataka part of India
}

\author{
Ijeri R. ${ }^{1}$, Navani A. ${ }^{2}$, Jyoti R.C. ${ }^{3}$, Navani S. ${ }^{4}$ \\ ${ }^{1}$ Dr. Raghavendra Ijeri, Assistant Professor, ${ }^{2}$ Dr. Ashwini Navani, Senior Resident, ${ }^{3}$ Dr. Jyoti RC., Senior Resident; above \\ authors are attached with Department of Ophthalmology, Sri B. M. Patil Medical College Hospital and Research Centre, \\ Vijayapur Karnataka, India, ${ }^{4}$ Dr. Suresh Navani, Consultant Chennamma Eye Hospital, Kalburgi Karnataka, India \\ Corresponding Author: Dr. Raghavendra Ijeri, Assistant Professor, Department of Ophthalmology, Sri B M Patil Medical \\ College Hospital and Research Centre, Vijayapur Karnataka. India. E-mail: $\underline{\text { drraghu.ijeri@gmail.com }}$
}

\begin{abstract}
Aims: To find the causes of blindness in children of blind schools in North Karnataka part of India. Settings and Design: Observational study. Methods and Material: Total of 92 children of less than 16 years of age were examined. This study was conducted in 2 blind schools in 2 districts of north Karnataka. The causes were divided in accordance with the world health organization (WHO) programme for prevention of blindness proforma. Results: Congenital eye lesions affecting the globe were seen in $33.7 \%$, Retinal and corneal cause's $20.65 \%$ each and lenticular causes around $8.7 \%$. Nearly $23 \%$ causes for blindness were preventable or treatable. Conclusions: Congenital ocular anomalies were the leading cause for blindness; Preventable and treatable cause were also significant in number. Improvement in research to find congenital anomalies, improvement in nutrition, vaccination and early diagnosis and management of treatable diseases are required to decrease childhood blindness.
\end{abstract}

Keywords: Blindness, Children, Blind School, North Karnataka, India

\section{Introduction}

Blindness in children is an important health problem. Vision 2020 -Right to sight programme aims to reduce blindness among children by the year 2020. This programme aims to reduce the prevalence of avoidable vision impairment by $25 \%$ from 2010 to 2019 [1]. It is estimated that there were 1.5 million blind children in the world, more than 18 million children have low vision and more than 19 million children are visually disabled [2].

Blindness has a significant impact on the affected child's psychological, educational and socioeconomic experiences, during childhood and beyond. There are various causes for childhood blindness which varies with place, ethnicity, socioeconomic status etc. Children are often at school or staying with relatives and blind children may be in residential care, giving rise to limitations and biases in the results of such surveys. Children with multiple disabilities are usually not admitted to these schools they are usually home bound. Obtaining statistics of such children is very difficult; surveying every house for blind child will be only method to find out the true number of blind children. Blind school survey may not give the true estimate for the causes of blindness but it may give the main causes for blindness.

Manuscript received: $5^{\text {th }}$ October 2019 Reviewed: $15^{\text {th }}$ October 2019

Author Corrected: $20^{\text {th }}$ October 2019

Accepted for Publication: 25 ${ }^{\text {th }}$ October 2019
The present study was conducted in blind schools of two districts in North Karnataka region of India. The main objective of the present study was to find out the causes of blindness in children present in the schools for the blind in these two districts.

\section{Materials and Methods}

The study was conducted in two blind schools of North Karnataka region of India.

This was an observational study.

This study was approved by the ethical committee of our university.

92 children less than 16 years of age were examined by ophthalmologist. Permission from principal of the school was taken before conducting the survey. Brief information on age, gender, and place were collected. Family history of blindness, age of onset of vision impairment, and history of consanguineous marriage of parents was documented. The visual acuity (VA) was tested separately for each eye and then for both eyes together. Functional vision was assessed for both the eyes together. Functional vision assessment was done to see whether the child could move around independently with the remaining vision (like moving in well illuminated room in between two chairs separated by 


\section{Original Research Article}

two meters), social contact (to recognize familiar faces from two meters), and near vision (by testing whether the child identifies any $5 \mathrm{~mm}$ objects from 30 centimetres) [3]. Anterior segment examination was performed using a torch, loupe. Dilated fundus examination was done using indirect ophthalmoscope whenever indicated. The World Health Organization Program for Prevention of Blindness (WHO/PBL) eye examination record for children with blindness was used to categorize the causes of blindness and to note down the findings, with the help of definitions given in it [4]. The structure of the eye and the diseases affecting both eyes of all the children noted. Any form of treatment required for the children may be spectacle correction, low vision aids, or any surgery required was noted; Children requiring further investigations and treatment were referred to our tertiary care hospital for further management.

\section{Results}

A total of 92 children were examined at the two schools in north Karnataka. The majority were aged between 6 to 16 years. 49 $(53.3 \%)$ children were male and 43(46.7\%) were females. Mean age of the children was 10.2+/- 2.2. Levels of VA for the 92 children attending these schools for the blind, in accordance with the WHO criteria ${ }^{[4]}$ for category of vision loss are shown in Table 1.

\section{Table-1: Categories of visual loss}

\begin{tabular}{|c|c|c|}
\hline Visual acuity & Who category & Number of children. \\
\hline $6 / 5-6 / 18$ & No Impairment & 0 \\
$<6 / 18-6 / 60$ & Impairment & 0 \\
$<6 / 60-3 / 60$ & Severe impairment & 60 \\
$<3 / 60-$ Perception of Light & Blind & 32 \\
No Perception of Light & Blind & 0 \\
\hline
\end{tabular}

Among 92 children who had blindness, anophthalmos, microphthalmos, and phthisis were the most frequent ocular defects leading to visual loss (Table 2). Retinal and corneal diseases were the second most common in the present study.

Among 92 children who had blindness, anophthalmos, microphthalmos, and phthisis were the most frequent ocular defects leading to visual loss (Table 2) (Figure 1).

Table-2: Various causes for blindness and their percentage.

\begin{tabular}{|l|c|c|}
\hline Anatomical site & Number & Percentage \\
\hline Whole Globe & 31 & 33.7 \\
\hline Anophthalmos & 8 & 5.7 \\
\hline Mircoophthalmos & 18.57 \\
\hline Phthisis & 19 & 20.65 \\
\hline Cornea & 5 & 5.43 \\
\hline Staphyloma & 12 & 13.04 \\
\hline Opacity & 2 & 2.17 \\
\hline Others & 8 & 8.70 \\
\hline Lens & 3 & 3.26 \\
\hline Cataract & 2 & 2.17 \\
\hline Aphakia & 3 & 3.26 \\
\hline Pseudophakia & 4 & 4.35 \\
\hline Congenital Glaucoma & 19 & 20.65 \\
\hline Retina & 6 & 6.52 \\
\hline Retinitis Pigmentosa & 8 & 8.70 \\
\hline Retinochoroidal scar/Dystrophy & 5 & 5.43 \\
\hline Retinal Detachment & 5 & 5.43 \\
\hline Optic Atrophy & 6 & 6.52 \\
\hline Coloboma involving Optic disc and macula & & \\
\hline
\end{tabular}




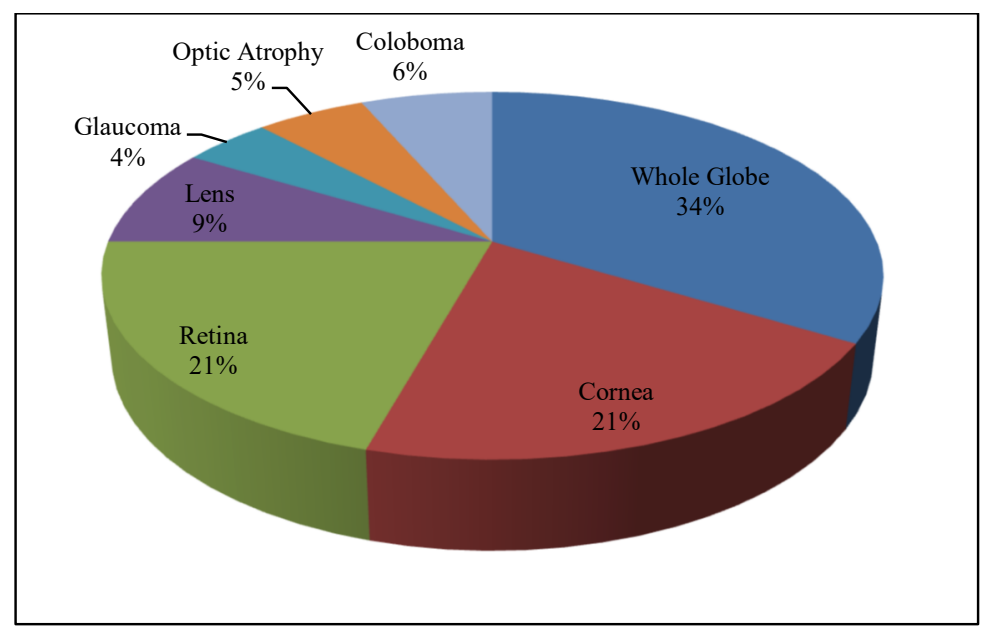

Fig-1: Anatomical causes for blindness (in Percentage).

Retinal diseases were the second most common affecting $20.65 \%$ of cases. Of the 19 children with retinal problems, $8(8.7 \%)$ had dystrophy, $6(6.52 \%)$ had retinitis pigmentosa and $5(5.43 \%)$ had retinal detachment. About 19 children had blindness due to corneal diseases, corneal opacity was seen in $12(13.04 \%)$ children, staphyloma seen in 5 children and other corneal diseases in 2 children. Cataract was seen in 3 children, phakia and pseudophakia in 2 and 3 children respectively. Congenital glaucoma was seen in $4(4.35 \%)$ children. Optic atrophy was seen in $5(5.43 \%)$ children. Coloboma involving optic disc and macula was seen in $6(6.52 \%)$ children.

Table-3: Preventable or treatable cause for blindness.

\begin{tabular}{|l|c|c|}
\hline Cause & Number of children & Percentage \\
\hline Preventable Causes & & 8.70 \\
\hline Vitamin A deficiency \& Measeles & 8 & 2.17 \\
\hline Ophthalmia Neonatorum & 2 & 8.70 \\
\hline Treatable Causes & 8 & 4.35 \\
\hline Cataract and related causes & 4 & \\
\hline Glaucoma/Buphthalmos & & \\
\hline
\end{tabular}

The avoidable causes of blindness were mainly vitamin A deficiency, ophthalmia neonatorum, blindness secondary to measles (Table 3). Vitamin A was an important avoidable cause of visual loss in children. Glaucoma / buphthalmos, cataract and its surgery related complications were the other causes which could have been treated which had led to blindness. 21 (22.83\%) children had preventable or treatable cause for blindness due to various factors as shown in Table 4.

Table-4: Percentage of blindness due to major causes in different studies

\begin{tabular}{|c|c|c|c|c|}
\hline Disease & Andhra Pradesh & Delhi & Maharashtra & Present Study \\
\hline Whole Globe & 41.4 & 27.4 & 41.3 & 33.7 \\
\hline Retina & 18.9 & 15.1 & 11.2 & 20.65 \\
\hline Cornea & 8.1 & 21.7 & 22.2 & 20.65 \\
\hline
\end{tabular}

\section{Discussion}

Blind school studies help us to examine many children within a very small amount of time. It is less expensive and can be done with limited amount of manpower and it may provide very good information about the causes for blindness in children in any given area. It is known from previous studies that findings of community-based samples are comparable with that obtained from blind school.
The present study attempted to know the diseases causing blindness among children of the blind schools in two districts of north Karnataka part of India. In this study it was found that congenital ocular anomalies like anophthalmos, microphthalmos, coloboma were more common compared to other eye diseases causing blindness. This is common finding in many studies done previously in India [5-7]. 


\section{Original Research Article}

The causes for congenital factors may be genetic, hereditary or intrauterine factors. Some studies have attributed these conditions to the consanguineous marriage which was seen in few patients in the present study.

One hypothesis has been that microphthalmos, anophthalmos, and coloboma are due deficiency of vitamin $\mathrm{A}$ in mother and defects in genes that control retinoic acid pathway [7]. Other causes for these conditions may be chromosomal abnormalities [8], intrauterine infections, drug abuse, alcohol, hyperthermia, maternal hypothyroidism $[9,10]$, exposure to pesticides [11]. Most of the studies done in India have ocular anomalies like phthisis, microphthalmos and anophthalmos more common than any other eye disease [5-7].

There were equal numbers of cases with corneal and retinal blindness (Table 4). Major causes for corneal blindness were due to vitamin A deficiency: the combination of diarrhoea, malnutrition and measeals cause corneal blindness. Retinal diseases like degenerations, retinitis pigmentosa were the common causes for blindness. Consanguineous marriage may be cause for some of these diseases. The table 5 demonstrates the percentage of blindness due to various causes in different studies [5-7].

Cataract was seen in few children who also had developed nystagmus suggesting long duration of opacity of lens. Even in few patients with pseudophakia and aphakia vision improvement was not seen. This might be due to delay in surgical intervention, posterior capsular opacification and onset of ambylopia. Early intervention in children having cataract is a must. School eye screening initiative under District blindness control society (DBCS) programme will help us to diagnose children with cataract at an earlier stage and treat them.

Congenital glaucoma and other congenital lesions like coloboma of the choroid involving optic disc and macula are very difficult to diagnose and treat in the early. In the present study preventable and treatable blindness was seen in $22.83 \%$ children. Hence steps like high immunisation coverage to prevent diseases like measles, educating mothers about significance and advantages of breast feeding, educating parents about nutrition and maintaining health; all these will help in reducing the number of children suffering from preventable blindness.

Community health workers should be trained to diagnoses basic signs of diseases like vitamin A deficiency, conjunctivitis, cataract etc which can help in reducing the childhood blindness. Improving socio economic status and education level of parents will help in reducing the blindness caused due to malnutrition.
Hereditary and genetic factors for blindness can be reduced by avoiding consanguineous marriages, genetic testing during pregnancy in parents having blind children. Regular antenatal check up should be done. Treatable blindness like cataract, glaucoma can be diagnosed early by regular school screening programmes.

Paediatric ophthalmology units should be set up in all district hospitals and medical colleges which should cater to such patients. It is recommended to have well equipped one paediatric ophthalmology unit per ten million population [12].

No case of retinopathy of prematurity was observed in the present study but it is one of the important causes of blindness nowadays due to increase in survival of premature children need for screening of these children is a must. Even for children with Retinal detachment and ocular trauma development of vitreo-retinal services at affordable price will a good initiative.

Retinal prosthesis and retinal transplantation may become feasible and affordable in the future for children with retinal dystrophies. The aim of this study was to know the causes of blindness among children of blind school in North Karnataka region of India. This will help us to prioritize the resources allocation towards decreasing the percentage of blindness in this area.

The drawbacks of this study are that since it's not a population-based study the data collected may not represent the actual figure of blind children. Majority of children who are blind may also have other disabilities so they may not be admitted to the blind schools. People may not have the knowledge about blind schools and the ways to enrol their children in these schools

\section{Conclusions}

Congenital ocular anomalies were the leading cause for blindness; Preventable and treatable cause were also significant in number. Improvement in research to find congenital anomalies, improvement in nutrition, vaccination and early diagnosis and management of treatable diseases are required to decrease childhood blindness.

\section{What the study adds to the existing knowledge?}

In the present study, the causes of blindness were evaluated in northern part of Karnataka which is one of the backward part of India. It was found that majority of blindness was due to corneal and retinal blindness both had equal number of cases. The number of developmental causes were compared to previous studies. 


\section{Original Research Article}

There was more number of blindness due to retinal causes compared to previous published data. Corneal cases were almost equal to the previously published data. There might be increase in diagnosis of retinal cases at a younger age due to improvement in diagnostic modalities.

\section{Author's Contribution}

- Dr. Raghavendra Ijeri: Concepts, design, literature search, clinical studies, data acquisition, data analysis, statistical analysis, manuscript editing and review,

- Dr. Ashwini Navani: Concepts, design, literature search, clinical studies, data acquisition, data analysis, statistical analysis, manuscript editing and review

- Dr. Jyoti RC: Concepts, design, literature search, clinical studies, data acquisition, data analysis, manuscript editing and review

- Dr. Suresh Navani: Concepts, design, clinical studies, data acquisition, data analysis, manuscript editing and review

Funding: No funding sources

Conflict of interest: None declared

Ethical Approval: This study was approved by the Institutional Ethics Committee

\section{Acknowledgement}

Authors would like to thank the principal, staff, parents and children of the blind schools for their kind cooperation for this study.

\section{References}

1. World Health Organization. Global initiative for the elimination of avoidable blindness. WHO/PBL/97.61. Geneva: WHO, 1997.

2. Bourne RR, Flaxman SR, Braithwaite T, Cicinelli MV, Das A, Jonas JB, et al. Magnitude, temporal trends, and projections of the global prevalence of blindness and distance and near vision impairment: a systematic review and meta-analysis. Lancet Glob Health. 2017;5(9):888 897. doi: 10.1016/S2214-109X (17)30293-0.

3. Silver J, Gilbert CE, Spoerer P, Foster A. Low vision in east African blind school students: need for optical low vision services. $\mathrm{Br} \mathrm{J}$ Ophthalmol. 1995;79(9):814-820. doi: 10.1136/bjo.79.9.814.

4. Gilbert C, Foster A, Negrel AD, Thylefors B. Childhood blindness: a new form of recording causes of vision loss in children. Bull World Health Organ. 1993;71(5):485-489.

5. Titiyal JS, Pal N, Murthy GVS, Gupta SK, Tandon R, Vajpayee RB et al. Causes and temporal trends of blindness and severe visual impairment in children in schools for the blind in North India. Br J Ophthalmol. 2003;87(8):941-945. doi: 10.1136/bjo.87.8.941.

6. Gogate P, Deshpande M, Sudrik S, Taras S, Kishore H, Gilbert C. Changing pattern of childhood blindness in Maharashtra, India. Br J Ophthalmol. 2007;91(1):8-12. doi:10.1136/bjo.2006.094433.

7. Krishnaiah S, Subba RB, Lakshmi NK, Amit G.A survey of severe visual impairment in children attending schools for blind in a costal district of Andhra Pradesh in south India. Eye. 2012;26 (8):1065-1070. doi: 10.1038/eye. 2012.88

8. Kallen B, Tornqvist $\mathrm{K}$. The epidemiology of anophthalmia and microphthalmia in Sweden. Eur $\mathrm{J}$ Epidemiol. 2005; 20(4):345-350. doi:10.1007/s10654-0046880-1.

9. Sowden J, Taylor DT. Disorders of the eye as a whole. In: Taylor D, Hoyt CG, eds. Pediatric ophthalmology and strabismus. Philadelphia, USA: Elsevier Saunders, 2005; 206.

10. Vogt G, Puho E, Czeizel AE. A population-based casecontrol study of isolated ocular coloboma. Ophthalmic Epidemiol. 2005;12 (3): 191-197. doi:10.1080/0928658 0590969699.

11. Dolk H, Cuzick J, Busby A, Armstrong BG, Walls PH. Geographical variation in anophthalmia and microphthalmia in England, 1988-94. BMJ. 1998;317 (7163): 905-909. doi:10.1136/bmj.317.7163.905.

12. World Health Organization. Preventing blindness in children. Report of a WHO/IAPB scientific meeting. WHO/ PBL/00.71. Geneva: WHO, 2000.

\section{How to cite this article?}

Ijeri R., Navani A., Jyoti R.C., Navani S. Causes of blindness in children attending blind school in north Karnataka part of India. Trop J Ophthalmol Otolaryngol.2019;4(7):435-439.doi:10.17511/jooo.2019.i07.06 